\title{
Уголовно-правовые и уголовно-исполнительные аспекты применения отсрочки отбывания наказания
}

\author{
Н. Г. СКОБЕЛЕВА - лицО, прикрепЛенное к ФГБОУ ВО «Российский госу- \\ дарственный университет правосудия» для подготовки диссертации на со- \\ искание ученой степени кандидата юридических наук, старший инспектор \\ филиала № 17 ФКУ УИИ УФСИН России по г. Москве
}

\section{Р е ферат}

В статье всесторонне рассмотрены проблемные вопросы, связанные с отсрочкой отбывания уголовного наказания, а также проанализированы практические сложности реализации отсрочки отбывания наказания, дана краткая историческая справка о развитии института отсрочки отбывания наказания в отечественном уголовном законодательстве. Автор выделяет не только положительные, но и отрицательные условия, которые способны изменить содержание института отсрочки отбывания наказания. На основании изучения статистических данных Судебного департамента при Верховном Суде Российской Федерации о назначении отсрочки отбывания наказания и ее отмены, а также данных ФСИН России о состоящих на учете в уголовно-исполнительных инспекциях осужденных с отсрочкой отбывания наказания предлагается классифицировать отсрочку отбывания наказания по времени ее применения (на стадии вынесения приговора суда с последующим освобождением от реального отбывания наказания и на стадии исполнения приговора суда), рассматривается вопрос о применении отсрочки отбывания наказания осужденным, усыновившим детей или взявшим их под свою опеку и попечительство. Обосновывается целесообразность считать осужденных, к которым применена отсрочка отбывания наказания, уклоняющимися от воспитания ребенка, если они два и более раза в год были подвергнуты административной ответственности за нарушение общественного порядка.

Ключевые слова: отсрочка отбывания наказания; уголовно-исполнительные инспекции; осужденные, больные наркоманией; осужденные беременные женщины.

\subsubsection{8 - Уголовное право и криминология; уголовно-исполнительное право}




\section{Criminal law and penal aspects of the application of the suspension of sentence}

N. G. SKOBELEVA - Person attached to the Federal State Budgetary Educational Institution of Higher Education «Russian State University of Justice» for the preparation of a dissertation for the degree of PhD. in Law, Senior Inspector of branch No. 17 of the Federal State Institution the Penal Inspection of Russia in Moscow Region

\section{Abstract}

The article comprehensively examined the problematic issues related to the suspension of criminal sentence, and also analyzes the practical difficulties of implementing the suspension of criminal sentence, provides a brief historical background on the development of the institution of suspension of criminal sentence in domestic criminal law. The author identifies not only positive, but also negative conditions that can change the content of the institution of suspension of criminal sentence. Based on a study of the statistical data of the Judicial Department under the Supreme Court of the Russian Federation on the appointment of a suspension of criminal sentence and its cancellation as well as the data of the Federal Penal Service of Russia on convicts registered in the penal inspections with a suspension of criminal sentence, it is proposed to classify the suspension of criminal sentence by the time of its application (at the stage of sentencing the court, with subsequent release from the actual serving of the sentence and at the stage of the execution of the court sentence), the issue of the application of suspension of criminal sentence to convicts who have adopted children or who have taken them under their guardianship. There is is substantiated expediency of considering convicts, to whom suspension of criminal sentence is applied, evading from raising a child, if they have been subjected to administrative responsibility for violation of public order two or more times a year.

Key words: suspension of criminal sentence; penal inspections; convicted drug addicts; convicted pregnant women.

\subsubsection{8 - Criminal law and criminology; penal law}

Одной из форм проявления принципов гуманизма и индивидуализации уголовной ответственности в уголовном законодательстве выступает отсрочка отбывания наказания. Данный институт представляет собой особый вид освобождения от наказания, который устанавливает временный отказ государства от применения принудительных мер в отношении осужденного в связи с определенными обстоятельствами, такими как реализация конституционного права на охрану материнства и детства, предоставление возможности лечения осужденным, больным наркоманией, вместо отбывания наказания. Отсрочка отбывания наказания имеет целью защиту прав и интересов ребенка при ее применении в отношении осужденной женщины, женщины, имеющей ребенка в возрасте до четырнадцати лет, мужчины, имеющего ребенка в возрасте до четырнадцати лет и являющегося единственным родителем, а также побуждает осужденных, признанных больными наркоманией, к прохождению курса лечения от наркозависимости и медико-социальной реабилитации (ст. 82, 82.1 УК РФ). При при- менении отсрочки отбывания наказания у осужденного сохраняются социально полезные связи, в полной мере обеспечивается право детей на развитие и воспитание в родной семье.

Институт отсрочки отбывания наказания находит свое закрепление не только в нормах уголовного права России, но и в законодательстве большинства зарубежных государств. Однако необходимо принимать во внимание многообразие форм применения видов института отсрочки отбывания наказания в разных странах и существование близкого по содержанию института условного осуждения. Например, в Англии и Голландии под пробацией понимают саму отсрочку отбывания наказания, отождествляя ее с испытательным сроком. При этом можно выделить две основные разновидности отсрочки: простая отсрочка отбывания наказания (или с установлением испытательного срока) и отсрочка назначения наказания.

На развитие уголовного законодательства стран ближнего зарубежья и СНГ большое влияние оказали Уголовный кодекс 
РСФСР и Основы уголовного законодательства СССР. Свое отражение институт отсрочки отбывания наказания нашел в законах республик Азербайджан, Армения, Казахстан, Кыргызстан, Таджикистан, Беларусь и Украина. Единственным исключением стала Республика Узбекистан, в которой полностью отсутствует такое понятие, как отсрочка отбывания наказания в отношении беременных женщин и женщин, имеющих детей. Применение же отсрочки отбывания наказания в отношении мужчин, имеющих детей, предусмотрено только законодательствами Российской Федерации, республик Казахстан и Кыргызстан.

Анализ уголовного законодательства стран бывшего Советского Союза позволил сделать вывод о том, что институты отсрочки отбывания наказания не являются полностью идентичными. Существенную разницу в правовом регулировании образует максимальный возраст ребенка осужденной женщины, к которой применяется отсрочка. Например, минимальный возраст ребенка, до которого предоставляется отсрочка отбывания наказания, указан в уголовных кодексах республик Армения, Беларусь и Украина, и составляет он три года. Восьмилетний возраст детей как верхняя граница для предоставления отсрочки установлен в отношении осужденных женщин, проживающих на территории республик Азербайджан и Туркменистан. До четырнадцатилетнего возраста ребенка по аналогии с Россией отсрочку отбывания наказания получают осужденные граждане республик Казахстан и Кыргызстан.

При применении отсрочки отбывания наказания в ряде государств для осужденных женщин определяются условия, такие как возможность самостоятельно обеспечить надлежащие условия для воспитания ребенка или иметь семью, готовую принять ее с ребенком (например, в уголовном кодексе Республики Беларусь). Законодательство Польши, Украины, Германии, Болгарии, Испании, Франции, Дании и других стран предусматривает возложение на осужденного дополнительных территориальных ограничений или иных обязанностей: пройти курс лечения от заболевания, возместить ущерб, воздержаться от вождения транспортных средств или выполнять общественно полезные работы.

Близкая по содержанию к российской отсрочке отбывания наказания норма нашлась в Уголовном кодексе Сан-Марино. Она предусматривает отсрочку отбывания наказания беременным женщинам, женщине, имеющим малолетних детей, и в связи с болезнью.

Законом Российской Федерации от 12.06.1992 № 2988-I «О внесении изменений и дополнений в Исполнительно-трудовой кодекс РСФСР, Уголовный кодекс РСФСР, Уголовно-процессуальный кодекс РСФСР» впервые была установлена норма уголовного законодательства, предусматривающая отсрочку отбывания наказания беременным женщинам и женщинам, имеющим малолетних детей в возрасте до трех лет. В 1996 г. были внесены изменения в УК РФ. Новая статья предусматривала отсрочку отбывания наказания беременным женщинам и женщинам, имеющим малолетних детей в возрасте до восьми лет. В 2001 г. Федеральным законом № 25-Ф3 «О внесении изменений и дополнений в Уголовный кодекс, Уголовно-процессуальный кодекс, Уголовно-исполнительный кодекс РФ и другие законодательные акты РФ» было предоставлено право применения отсрочки отбывания наказания в отношении осужденных женщин, имеющих детей, не достигших возраста четырнадцати лет. Федеральный закон от 21.02.2010 № 16-Ф3 «О внесении изменений в отдельные законодательные акты Российской Федерации» определил, что отсрочка отбывания наказания применяется не только в отношении женщин, но и в отношении мужчин, имеющих детей и являющихся единственными родителями. Наконец, Федеральным законом от 07.12.2011 № 420-Ф3 данный институт был дополнен отсрочкой отбывания наказания осужденным, больным наркоманией.

Условиями предоставления отсрочки отбывания наказания осужденным, больным наркоманией, являются, во-первых, впервые назначенное наказание в виде лишения свободы за совершение преступления, предусмотренного ч. 1 ст. 228, ч. 1 ст. 231 и ст. 233 УК РФ, во-вторых, желание самого осужденного, сформулированное в письменном виде в заявлении о добровольном прохождении курса лечения от наркомании, а также медицинской и социальной реабилитации. В то же время практика применения отсрочки больным наркоманией свидетельствует о том, что суды довольно редко применяют данную норму, используя в отношении этой категории осужденных в основном условное осуждение. По данным ФСИН России, на учетах в уголовно-исполнительных инспекциях в 2018 г. состояло 105 чел. Как следует из отчета о работе судов 
Судебного департамента при Верховном Суде Российской Федерации, за первое полугодие 2018 г. судами были применены 34 отсрочки отбывания наказания в отношении осужденных, больных наркоманией. Однако в первом полугодии 2018 г. судами Российской Федерации отмена отсрочки отбывания наказания больным наркоманией в связи с отказом от прохождения или нарушениями установленного курса лечения от наркомании и прохождения медикосоциальной реабилитации была назначена 27 осужденным, что составляет 79,41 \% от общего числа осужденных, к которым была применена норма ст. 82.1 УК РФ.

По мнению А. В. Денисовой, целесообразно применять отсрочку отбывания наказания осужденным больным наркоманией за совершение впервые также и иных преступлений небольшой и средней тяжести при наличии мотива, связанного с наркозависимостью [1]. Очевидно, что в данном случае к совершению преступления побуждает болезненная потребность в приобретении наркотических или психотропных средств для собственного употребления. Такое изменение позволит применить рассматриваемых институт к более широкому кругу осужденных.

Однако нужно признать, что далеко не все осужденные, больные наркоманией, способны самостоятельно эффективно проходить соответствующее лечение. В связи с этим целесообразно было бы предоставить суду возможность применять отсрочку отбывания наказания осужденным, больным наркоманией, с помещением на первоначальном этапе на стационарное лечение в соответствующие государственные медицинские центры.

Согласно ч. 3 ст. 82.1 УК РФ основанием освобождения от отбывания наказания является подтвержденная ремиссия, срок которой составляет не менее двух лет после прохождения медицинской и социальной реабилитации. Однако нормативно не определены медицинские учреждения, которые могут брать на себя полную ответственность за прохождение осужденными наркоманами не только медицинской, но и социальной реабилитации, а также объективно подтверждать ремиссию. Полагаем, что в такой роли должны выступать исключительно медицинские учреждения государственного или муниципального здравоохранения.

Одной из главных целей назначения отсрочки отбывания наказания беременной женщине, женщине и мужчине, имеющим малолетних детей, является намерение создать осужденным и, главным образом, ребенку максимально комфортные условия для жизни.

Так, в принятой Генеральной Ассамблеей ООН Конвенции о правах ребенка от 20.11.1959 говорится: «Ребенок для полного и гармоничного развития его личности нуждается в любви и понимании. Он должен, когда это возможно, расти на попечении и под ответственностью своих родителей и во всяком случае в атмосфере любви и материальной обеспеченности; малолетний ребенок не должен, кроме тех случаев, когда имеются исключительные обстоятельства, быть разлучаем со своей матерью».

В настоящее время наметилась тенденция к сокращению объема осужденных, в отношении которых применяется отсрочка отбывания наказания. Так, по данным ФСИН России, в 2013 г. на учете в УИИ состояло 8036 женщин и мужчин с отсрочкой отбывания наказания без учета осужденных, больных наркоманией, в 2017 г. этот показатель снизился до 6970 чел. На отчетный период 2018 г. количество осужденных с отсрочкой отбывания наказания составило 7315 чел. В процентном соотношении их доля от общего числа осужденных, состоящих на учете в УИИ, в вышеуказанные годы достигала $1,77 \%, 1,38 \%, 1,43 \%$ соотвественно.

Институт отсрочки отбывания наказания во многом схож с институтом условного осуждения. Так, осужденным назначается наказание, но приговор не приводится в исполнение. Суд отсрочивает его на определенный срок и устанавливает некие условия. Отметим, что условное осуждение является более мягкой мерой уголовно-правового характера по сравнению с отсрочкой отбывания наказания. Это во многом определяет сложившуюся судебную практику в части применения данных институтов.

По мнению М. С. Красильниковой, условия, необходимые для предоставления отсрочки отбывания наказания, в соответствии с действующим УК РФ можно классифицировать на две группы: положительные и отрицательные. При этом к положительным условиям можно отнести наличие беременности либо малолетнего ребенка, для осужденного мужчины дополнительным условием будет то, что он должен быть единственным родителем малолетнего ребенка. Проблем с установлением положительных условий предоставления отсрочки отбывания наказания практически нет, так как женщина подтверждает свою беременность 
медицинской справкой, а наличие ребенка можно доказать, представив свидетельство о его рождении. К группе отрицательных можно отнести условия, при которых отсрочка отбывания наказания не применяется, например осуждение лица к лишению свободы сроком более пяти лет за тяжкое или особо тяжкое преступление против личности и т. д. [2].

На наш взгляд, целесообразно было бы классифицировать предоставление осужденным отсрочки отбывания наказания по времени ее применения. Первую группу при этом образует применение отсрочки отбывания наказания на стадии вынесения приговора судом с последующим освобождением от реального отбывания наказания. Ко второй группе можно отнести реализацию судом отсрочки на стадии исполнения приговора суда с последующим освобождением от дальнейшего отбывания частично отбытого наказания.

Вопрос об отсрочке отбывания наказания рассматривается судом по ходатайству осужденного. Применение данного вида освобождения от реального отбывания наказания на определенный срок зависит от усмотрения суда и поэтому не является обязательным. Такое освобождение является условным, и условием при этом выступает соответствующее правопослушное поведение осужденного, свидетельствующее о проявлении заботы о своем ребенке и стремлении дать ему надлежащее воспитание. Отсрочка может быть отменена в случае, когда отпало основание ее применения: прерывание беременности, смерть малолетнего ребенка. Отсрочка также отменяется при совершении осужденным нового преступления. При этом суд назначает ему наказание по правилам, предусмотренным ст. 70 УК РФ.

Следует отметить, что граждане, которые усыновили или удочерили детей, также относятся к лицам, имеющим ребенка, потому что в ст. 137 Семейного кодекса Российской Федерации говорится о том, что такие лица приравниваются в правах к биологическим родителям. Кроме того, к лицам, имеющим детей, можно отнести граждан, взявших ребенка под опеку или попечительство. Семейное законодательство их не приравнивает к биологическим родителям или законным усыновителям, однако они тоже имеют цель обеспечить полной заботой и уходом приемных детей. Таким образом, возникает вопрос, имеют ли указанные лица права на применение к ним нормы ст. 82 УК РФ.
М. С. Красильникова отвечает на него положительно, указывая на то, что отсрочка отбывания наказания будет обеспечивать интересы как ребенка, так и родителя с учетом особенностей личности осужденного и характера совершенного им преступления [2].

Отметим, что на практике вопрос о предоставлении отсрочки отбывания наказания лицам, взявшим детей под опеку или попечительство, не рассматривается, так как это не регламентировано уголовным законодательством.

Мы разделяем мнение М. С. Красильниковой о том, что содержащееся в ст. 82 УК РФ нормативное указание о предоставление отсрочки осужденному мужчине, имеющему ребенка в возрасте до 14 лет, который должен являться единственным родителем, нарушает равенство граждан перед законом, поскольку в отношении осужденной женщины подобного условия в законе не прописано. На тот факт, что у ребенка не должно быть матери, указывает уголовный кодекс, употребляя лишь в отношении мужчин термин «родитель». При этом все негативные последствия назначения реального наказания мужчине, являющемуся единственным кормильцем в семье, но не являющемуся единственным родителем, лягут на его близких. Таким образом, при исключении отсрочки отбывания наказания данным мужчинам в неравном положении по сравнению с осуждением одинокого мужчины или осуждением матери оказывается не только ребенок, но и вся семья осужденного [2].

Контролирующим органом за осужденным с отсрочкой отбывания наказания является уголовно-исполнительная инспекция по месту его жительства. При исполнении данной меры уголовно-правового характера сотрудники УИИ руководствуются ст. 177, 178, 178.1 УИК РФ, а также другими нормативно-правовыми актами.

Согласно п. 137 приказа Минюста России от 20.05.2009 № 142 «Об утверждении инструкции по организации исполнения наказаний и мер уголовно-правового характера без изоляции от общества» осужденного следует считать уклоняющимся от воспитания ребенка, если он оставил его в родильном доме, или передал в детский дом, или ведет антиобщественный образ жизни и не занимается должным воспитанием ребенка и уходом за ним, без уважительной причины оставил ребенка родственникам или иным лицам, скрылся либо совершает иные действия (бездействие), свидетельствующие об уклонении от воспитания ребенка. Дан- 
ный перечень требований, предъявляемых к поведению осужденного, наказание которого отсрочено в связи с наличием малолетних детей, является исчерпывающим. Поэтому если родитель исполняет свои родительские обязанности по воспитанию ребенка, но вместе с тем, например, злоупотребляет алкоголем или нарушает общественный порядок, то такое отрицательное поведение освобожденного не может стать основанием для отмены судом отсрочки отбывания наказания. Хотя правильное воспитание детей лицом, ведущим аморальный и антиобщественный образ жизни, представить сложно.

Интервьюирование некоторых сотрудников уголовно-исполнительных инспекций УФСИН России по г. Москве показало, что часть осужденных, не уклоняющихся от воспитания ребенка, совершают различные нарушения общественного порядка и привлекаются к административной ответственности. Такие действия не предусматривают вынесения письменного предупреждения со стороны контролирующих органов. Представляется правильным считать уклоняющимися от воспитания ребенка осужденных, которые два и более раза в год были подвергнуты административной ответственности за нарушения общественного порядка, предусмотренные гл. 20 КоАП РФ.

Таким образом, нормы, регламентирующие отсрочку отбывания наказания, занимают важное место в уголовном и уголовно-исполнительном законодательстве и нуждаются в дальнейшем совершенствовании. Расширение и уточнение круга лиц, к которым применима отсрочка отбывания наказания, за счет включения в перечень граждан, усыновивших, удочеривших детей или взявших детей под опеку или попечительство, позволит наиболее эффективно и полно реализовать принцип равенства, а также закрепленную в ст. 7 Конституции Российской Федерации поддержку семьи, материнства, отцовства и детства.

\section{СПИСОК ЛИТЕРАТУРЫ}

1. Денисова, А. В. Критерии корректности уголовно-правовых норм / А. В. Денисова // Российская юстиция. 2017. - № 11. - C. 21-24.

2. Красильникова, М. С. Некоторые вопросы уголовно-правового регулирования отсрочки отбывания наказания (ст. 82 УК РФ) / М. С. Красильникова // Вестник Кемеровского государственного университета. - 2013. № 4 (56). - C. 273-277.

\section{REFERENCES}

1. Denisova A. V. Kriterii korrektnosti ugolovno-pravovyh norm [Criteria for the correctness of criminal law]. Rossijskaya yusticiya - Russian justice, 2017, no. 11, pp. 21-24. (In Russ.)

2. Krasil'nikova M. S. Nekotorye voprosy ugolovno-pravovogo regulirovaniya otsrochki otbyvaniya nakazaniya (st. 82 UK RF) [Some issues of the criminal law regulation of deferment of punishment (Article 82 of the Criminal Code of the Russian Federation)]. Vestnik Kemerovskogo gosudarstvennogo universiteta - Bulletin of the Kemerovo State University, 2013, no. 4 (56), pp. 273-277. (In Russ.). 